\title{
Controlled drug delivery for glaucoma therapy using montmorillonite/Eudragit microspheres as an ion-exchange carrier
}

This article was published in the following Dove Press journal: International Journal of Nanomedicine

\author{
Shuangyan Tian' \\ Juan $\mathrm{Li}^{\prime}$ \\ Qi Tao ${ }^{2,3}$ \\ Yawen Zhao' \\ Zhufen Lv ${ }^{4}$ \\ Fan Yang' \\ Haoyun Duan ${ }^{5}$ \\ Yanzhong Chen ${ }^{4}$ \\ Qingjun Zhou ${ }^{5}$ \\ Dongzhi Hou' \\ 'Guangdong Engineering and \\ Technology Research Center of \\ Topical Precise Drug Delivery System, \\ College of Pharmacy, Department \\ of Pharmaceutics, Guangdong \\ Pharmaceutical University, ${ }^{2}$ CAS \\ Key Laboratory of Mineralogy and \\ Metallogeny, ${ }^{3}$ Guangdong Provincial \\ Key Laboratory of Mineral Physics \\ and Materials, Guangzhou Institute \\ of Geochemistry, Chinese Academy \\ of Sciences, ${ }^{4}$ Guangdong Provincial \\ Key Laboratory of Advanced Drug \\ Delivery Systems, Guangdong \\ Pharmaceutical University, Guangzhou, \\ ${ }^{5}$ State Key Laboratory Cultivation \\ Base, Shandong Provincial Key \\ Laboratory of Ophthalmology, \\ Shandong Eye Institute, Shandong \\ Academy of Medical Sciences, \\ Qingdao, China
}

Correspondence: Dongzhi Hou Guangdong Pharmaceutical University, Guangzhou Higher Education Mega Center, 280 Wai Huan Dong Road, Guangzhou, 510006, China

Tel +86 I80 263। 2508

Fax +86 2039352117

Email houdongzhi406@I63.com
Background: Glaucoma is a serious eye disease that can lead to loss of vision. Unfortunately, effective treatments are limited by poor bioavailability of antiglaucoma medicine due to short residence time on the preocular surface.

Materials and methods: To solve this, we successfully prepared novel controlled-release ionexchange microparticles to deliver betaxolol hydrochloride (BH). Montmorillonite/BH complex (Mt-BH) was prepared by acidification-intercalation, and this complex was encapsulated in microspheres (Mt-BH encapsulated microspheres [BMEMs]) by oil-in-oil emulsion-solvent evaporation method. The BH loaded into ion-exchange Mt was $47.45 \% \pm 0.54 \%$. After the encapsulation of Mt-BH into Eudragit microspheres, the encapsulation efficiency of BH into Eudragit microspheres was $94.35 \% \pm 1.01 \%$ and $\mathrm{BH}$ loaded into Eudragit microspheres was $14.31 \% \pm 0.47 \%$.

Results: Both Fourier transform infrared spectra and X-ray diffraction patterns indicated that $\mathrm{BH}$ was successfully intercalated into acid-Mt to form Mt-BH and then Mt-BH was encapsulated into Eudragit microspheres to obtain BMEMs. Interestingly, in vitro release duration of the prepared BMEMs was extended to 12 hours, which is longer than both of the BH solution (2.5 hours) and the conventional BH microspheres (5 hours). Moreover, BMEM exhibited lower toxicity than that of BH solution as shown by the results of cytotoxicity tests, chorioallantoic membrane-trypan blue staining, and Draize rabbit eye test. In addition, both in vivo and in vitro preocular retention capacity study of BMEMs showed a prolonged retention time. The pharmacodynamics showed that BMEMs could extend the drug duration of action.

Conclusion: The developed BMEMs have the potential to be further applied as ocular drug delivery systems for the treatment of glaucoma.

Keywords: glaucoma, montmorillonite, controlled release, betaxolol hydrochloride, preocular retention, microspheres

\section{Introduction}

Glaucoma is a slowly progressive atrophy of the optic nerve, characterized by loss of peripheral visual function and an excavated appearance of the optic disc by ophthalmoscopy. ${ }^{1}$ It is commonly considered as the second leading cause of blindness and about 60.5 million individuals have been affected worldwide. ${ }^{2}$ High intraocular pressure (IOP) is the main risk factor, which leads to the degeneration of axons from the retinal ganglion cells. Therefore, many kinds of IOP lowering medications are used to manage the disease symptoms, such as timolol, betaxolol, epinephrine, pilocarpine, and dorzolamide. ${ }^{3}$ However, effective treatments are often limited owing to poor bioavailability of topically administered ocular drugs caused by a number of factors, including rapid tear turnover, transient residence time in the cul-de-sac, and washout 
of tear. ${ }^{4,5}$ These factors lead to rapid elimination of the drugs from the precorneal area. Thus, glaucoma therapy is still a significant challenge for clinical applications due to the absence of adequate drug concentration and short residence duration in the ocular tissues. In order to solve the problem, many significant efforts toward advanced ocular drug delivery systems have been made over the last few decades. Thermosensitive hydrogels, implants, and particulate carrier systems have been investigated to sustain the release of drug, prolong retention time on the ocular surface, and improve bioavailability. ${ }^{6,7}$ Among these strategies, particulate carrier systems have gained considerable attention for ocular applications due to their convenient application of liquid form, prolonged residence time on the cornea, and low irritability. ${ }^{8}$

Microspheres, as particulate carrier systems, are promising drug delivery systems for eye application because of their properties of easy preparation, wide compatibility, and sustained release..$^{9-14}$ There are several methods that can be used to form microspheres from polymers, such as spray drying method, emulsion-solvent evaporation method, and phase separation method. One of the most common approaches for the preparation of microparticles for site-specific drug delivery is based on emulsification solvent evaporation, including oil-in-water, oil-in-oil (O/O), and water-in-oil-inwater. For water-soluble drugs and expensive protein drugs, $\mathrm{O} / \mathrm{O}$ is the most popular method due to its flexibility (easy to operate), high efficiency (high entrapment rate and drug loading rate [DL\%]), and reduced burst release. ${ }^{15-17}$ Eudragit RS and RL polymers are commonly used for the preparation of controlled-release drug forms due to their positive charge, which can allow a longer residence time on the corneal surface. ${ }^{18}$ They are two copolymers synthesized from acrylic and metacrylic acid esters, containing an amount of quaternary ammonium groups between $4.5 \%-6.8 \%$ and $8.8 \%-12 \%$ for RS and RL, respectively. ${ }^{19}$ Previous studies have demonstrated that Eudragit has been used as inert carriers to formulate controlled-release delivery systems of nonsteroidal antiinflammatory drugs, such as ibuprofen and flurbiprofen. ${ }^{19,20}$

More recently, many considerable attempts have been made to improve the preparation method of microspheres. For example, hybrid materials combining polymers with inorganic solids were synthesized to obtain a functional delivery system. Montmorillonite (Mt), as an effective inorganic solid, has been proposed for modulating drug release properties as in our previous studies, due to its good biocompatibility, high adsorption ability, and high cation exchange capacity (CEC). Previous results indicated that the release duration and burst release could be effectively improved by integrating $\mathrm{Mt}$ with polymers to form nanocomposites or microspheres. ${ }^{21-25}$ Meanwhile, Mt is a 2:1 type swelling phyllosilicate with fine grain and large interlayer-planar spacing, which can allow cationic drug molecules intercalating into this space through ion-exchange method. It was reported that $\mathrm{Mt}$ intercalated with 5-fluorouracial and ibuprofen effectively improved the sustained release and loading capacity of drug molecules. ${ }^{26-28}$ Though this improvement is encouraging, there are a few reports that focus on the anomalous diffusion mechanism of drug release from these nanocomposites and/or microspheres. ${ }^{29}$ Therefore, a detailed release mechanism is required to interpret the release process of drug molecules for guiding future research of microspheres.

Inspired by the advantages of $\mathrm{Mt}$, microspheres, and Eudragit RS/RL polymers, in this paper, we have made an effort to integrate Mt with Eudragit microspheres as an ocular drug carrier. To the best of our knowledge, there is no related report about Mt/Eudragit microspheres yet, as controlled drug delivery systems for glaucoma therapy. Herein, betaxolol hydrochloride $(\mathrm{BH})$, a $\beta_{1}$ antagonist for glaucoma therapy, was investigated as a model drug. Acidification-intercalation and $\mathrm{O} / \mathrm{O}$ emulsion-solvent evaporation technique were used for the preparation of the $\mathrm{Mt} / \mathrm{BH}$ complex $(\mathrm{Mt}-\mathrm{BH})$ and Mt-BH encapsulated microspheres (BMEMs), respectively. The structural characteristics of Mt-BH and BMEMs were measured by Fourier transform infrared spectra (FTIR), $\mathrm{X}$-ray diffraction (XRD), and scanning electron microscopy (SEM). The release mechanism of BH from BMEMs was investigated. The thiazolyl blue method (MTT), chorioallantoic membrane-trypan blue staining (CAM-TBS) assay, and Draize test were used for determining the irritation of BMEMs. Moreover, the preocular retention capacity was investigated by in vivo and in vitro experiments. Finally, pharmacodynamic observations were conducted to investigate the capacity of reducing intraocular pressure (IOP).

\section{Materials and methods Materials}

Mt with a CEC of $90 \mathrm{mmol} \cdot \mathrm{g}^{-1}$ was bought from Zhejiang Sanding Technology Co, Ltd (Shaoxing, China). BH was purchased from Hao Industrial (Shandong, China). Eudragit RS100 and RL100 were purchased from Evonik Degussa (Germany). 1-(4,5-Dimethylthiazol-2-yl)-3,5diphenylformazan (MTT) and all components of buffer solutions were from Sigma-Aldrich Co (St Louis, MO, USA). All other chemical reagents used in the study were of high performance liquid chromatography (HPLC) or 
analytical grade. Human immortalized cornea epithelial cells (iHCECs) were kindly provided by Shandong Eye Institute (Qingdao, China) and the study was approved by the Ethics Committee of Shandong Eye Institute.

\section{Sample preparation}

\section{Preparation of $\mathrm{Mt}-\mathrm{BH}$}

Mt was activated by $5 \% \mathrm{H}_{2} \mathrm{SO}_{4}$ for 0.5 hours at $70^{\circ} \mathrm{C} .{ }^{24} \mathrm{After}$ the exchange of interlayer metal ions with $\mathrm{H}^{+}$, Mt was ultrasonically treated for 5 minutes to obtain ultrafine montmorillonite treated with acid (acid-Mt) particles. Then, the acid-Mt was centrifuged and washed with deionized water until the $\mathrm{pH}$ was equal to 7.0. The solids were dried at $100^{\circ} \mathrm{C}$ and crushed.

One gram acid-Mt and $3 \mathrm{~g} \mathrm{BH}$ were added to $1,000 \mathrm{~mL}$ deionized water, and the adsorption process was carried out in a water bath $\left(50^{\circ} \mathrm{C}\right)$ for 6 hours. After washing, centrifuging, and drying, solid products of Mt-BH were obtained. DL\% (Q) was determined with HPLC (Agilent 1200; Agilent Technologies, Santa Clara, CA, USA) using Equation 1:

$$
Q=\frac{\left(C_{0}-C\right) \times V_{\mathrm{BH}}}{M_{\text {acid-Mt }}} \times 100 \%
$$

where $C_{0}$ and $C\left(\mathrm{mg} \cdot \mathrm{mL}^{-1}\right)$ are the $\mathrm{BH}$ concentrations before and after DL into acid-Mt, respectively, $M_{\text {acid-Mt }}(\mathrm{mg})$ is the mass of acid-Mt, and $V_{\mathrm{BH}}(\mathrm{mL})$ is the volume of the $\mathrm{BH}$ solution.

The HPLC conditions were as follows: the $\mathrm{BH}$ concentration was determined by HPLC. Ultimate ${ }^{\circledR}$ XB-C18 column (Welch, Austin, TX, USA; 4.60×250 mm, $5 \mu \mathrm{m}$ ) was used. The mobile phase was acetonitrile/trimethylamine $(30 / 70, \mathrm{v} / \mathrm{v})$ with $\mathrm{pH} 3.0$. The detector wavelength, flow rate, column temperature, and injection volume were $275 \mathrm{~nm}$, $1 \mathrm{~mL} \cdot \mathrm{min}^{-1}, 25^{\circ} \mathrm{C}$, and $20 \mu \mathrm{L}$, respectively.

\section{Preparation of BMEMs}

BMEMs were prepared by $\mathrm{O} / \mathrm{O}$ emulsion-solvent evaporation method. ${ }^{30}$ Briefly, Eudragit RL/RS 100, triethyl citrate, glycerinum, Tween $80, \mathrm{BH}$, and Mt-BH were dispersed in a mixed organic solvent (acetonitrile and dichloromethane [DCM] with a volume ratio of 4:1) as an internal oil phase. Span 80 was dispersed in light liquid paraffin as an external oil phase. The internal oil phase was homogenized at a rate of $10,000 \mathrm{r} \cdot \mathrm{min}^{-1}$ for 5 minutes to obtain an ultrafine dispersed suspension. Afterward, the internal oil phase was added into the external oil phase drop-by-drop to form a mixed emulsion $(\mathrm{O} / \mathrm{O})$. At room temperature $(\mathrm{RT})$, the emulsion was stirred at a rate of $800 \mathrm{r} \cdot \mathrm{min}^{-1}$ for 4-8 hours until the organic solvent completely evaporated. After washing with n-hexane 7-9 times, BMEMs were dried with pumping filtration. The preparation process and construction of BMEMs are shown in Figure 1.

\section{Physicochemical characteristics of BMEMs Entrapment efficiency (EE\%) and DL\%}

BMEMs $(30 \mathrm{mg})$ were dissolved in $1 \mathrm{~mL}$ of DCM with the help of ultrasonic treatment. BH was extracted by $30 \mathrm{~mL}$ of deionized water through a vortex process. After centrifuging at 3,000 r.min ${ }^{-1}$ for 10 minutes, the diluted supernatant was measured by HPLC at $275 \mathrm{~nm}$. EE\% and DL\% of BMEMs were calculated using Equations 2 and 3, respectively:

$$
\begin{array}{r}
\mathrm{EE} \%=\frac{\mathrm{m}_{\mathrm{BH}}^{\prime}}{\mathrm{m}_{\mathrm{BH}}} \times 100 \% \\
\mathrm{DL} \%=\frac{\mathrm{m}_{\text {BH }}^{\prime}}{\mathrm{m}_{\text {BMEM }}} \times 100 \%
\end{array}
$$

where $\mathrm{m}_{\mathrm{BH}}^{\prime}$ is the weight $(\mathrm{mg})$ of $\mathrm{BH}$ encapsulated in BMEMs, $\mathrm{m}_{\mathrm{BH}}$ is the weight $(\mathrm{mg})$ of initially added $\mathrm{BH}$, and $\mathrm{m}_{\text {BMEM }}$ is the weight ( $\mathrm{mg}$ ) of BMEMs.

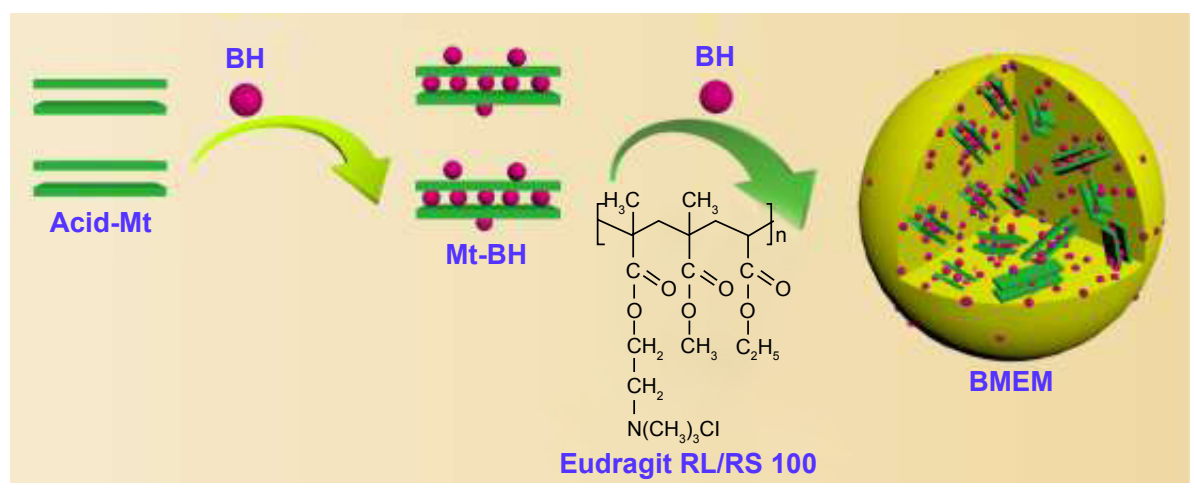

Figure I A schematic of the preparation process of BMEMs. BMEMs represent Eudragit microspheres incorporated Mt-BH.

Abbreviations: Acid-Mt, montmorillonite treated with acid; $\mathrm{BH}$, betaxolol hydrochloride; $\mathrm{BMEM}$, betaxolol hydrochloride encapsulated microsphere; Mt, montmorillonite; $\mathrm{Mt}-\mathrm{BH}$, betaxolol hydrochloride loaded into montmorillonite. 


\section{Characterization}

FTIR was measured by a Vertex-70 FTIR spectrometer (Bruker Optik GmbH, Ettlingen, Germany) at RT in the range of $400-4,000 \mathrm{~cm}^{-1}$ with a resolution of $4 \mathrm{~cm}^{-1}$ and using 64 scans. XRD patterns were obtained using a Bruker D8 advance diffractometer (Bruker Optik $\mathrm{GmbH}$ ) from $2^{\circ}$ to $15^{\circ}$ with a scanning rate of $2^{\circ} \cdot \mathrm{min}^{-1}$, by using $\mathrm{CuK} \alpha$ radiation with a generator voltage of $40 \mathrm{kV}$ and a generator current of $40 \mathrm{~mA}$. The morphology of all samples was determined by using Hitachi S-3400N SEM (Hitachi Ltd, Tokyo, Japan) at an accelerating voltage of $20 \mathrm{kV}$. All samples were dried and coated with gold before scanning.

\section{In vitro release studies}

In vitro drug release experiments were conducted by using dialysis bag in dialysis medium at $34^{\circ} \mathrm{C}$. Exactly $6.7 \mathrm{~g} \mathrm{NaCl}$, $2.0 \mathrm{~g} \mathrm{NaHCO}_{3}, 0.06 \mathrm{~g} \mathrm{CaCl}_{2}$, and $1.38 \mathrm{~g} \mathrm{KCl}_{\text {were dissolved }}$ in $1,000 \mathrm{~mL}$ deionized water to prepare the dialysis medium (artificial tears). Briefly, BMEMs $\left(2 \mathrm{~mL}, 2.8 \mathrm{mg} \cdot \mathrm{mL}^{-1}\right)$, conventional BH microspheres $\left(2 \mathrm{~mL}, 2.8 \mathrm{mg} \cdot \mathrm{mL}^{-1}\right.$, absence of $\mathrm{Mt})$, and $\mathrm{BH}$ solution $\left(2 \mathrm{~mL}, 2.8 \mathrm{mg} \cdot \mathrm{mL}^{-1}\right)$ were enclosed in the dialysis bag and then put into $35 \mathrm{~mL}$ artificial tears. At designated time intervals, $5 \mathrm{~mL}$ of the sample was withdrawn from the bag and immediately replaced with the same volume of fresh artificial tears. The amount of drug released was determined by HPLC. The release behavior and mechanism of drug from BMEMs were analyzed.

\section{Cytotoxicity test}

To assess the cytotoxicity of BMEMs, iHCECs were used in the present study. The cells were grown in DMEM/F-12 along with $10 \%(\mathrm{v} / \mathrm{v})$ fetal bovine serum, $0.1 \mathrm{mg} \cdot \mathrm{mL}^{-1}$ streptomycin, and $1,000 \mathrm{IU} \cdot \mathrm{mL}^{-1}$ penicillin under $5 \% \mathrm{CO}_{2}$ at $37^{\circ} \mathrm{C}$ (series $\Pi$ water jacket). ${ }^{31}$ When cells achieved $>80 \%$ confluence, they were exposed to formulations along with media. Different concentrations and durations of the formulations were evaluated by MTT assay. The experiment was performed in four groups: $\mathrm{G}_{1}=$ control group, $\mathrm{G}_{2}=\mathrm{BH}$ solution group, $\mathrm{G}_{3}=$ blankBMEM group, and $\mathrm{G}_{4}=$ BMEM group. Each test group had six different concentrations $(0.28,0.56,0.84,1.40,2.24$, and $\left.2.8 \mathrm{mg} \cdot \mathrm{mL}^{-1}\right)$. After exposure to formulations for 120 minutes, the medium was removed and the cell was carefully rinsed with phosphate-buffered saline. Then, $5 \mathrm{mg} \cdot \mathrm{mL}^{-1}$ MTT was added to each well and further incubated for 4 hours. Finally, the resulting formazan crystals were dissolved by dimethyl sulfoxide and measured by a spectrophotometer at $490 \mathrm{~nm}$. Cell viability was calculated using Equation 4:

$$
\text { Cell viability } \%=\frac{A^{\prime}}{A_{0}} \times 100 \%
$$

where $\mathrm{A}^{\prime}$ and $\mathrm{A}_{0}$ are the absorbance of the test and control groups, respectively.

\section{CAM-TBS test}

An alternative for the Draize rabbit eye test is the CAM-TBS test, which is an inexpensive and sensitive assay established for ophthalmic irritancy; it has shown good correlation to in vivo irritation studies. ${ }^{32}$ Briefly, fertilized hen's eggs were incubated in the horizontal position to ensure correct positioning of the embryo (away from the CAM) at $37^{\circ} \mathrm{C} \pm 0.5^{\circ} \mathrm{C}$ and $40 \% \pm 5 \%$ relative humidity for 9 days..$^{33}$ On the 10 th day, the section of egg shell above the airspace was removed and several drops of saline solution were added onto the shell membrane with a pipette. Then, the inner membrane was carefully removed to expose the CAM without damaging the underlying CAM. BMEMs (300 $\left.\mu \mathrm{L}, 2.8 \mathrm{mg} \cdot \mathrm{mL}^{-1}\right)$, blank-BMEMs (300 $\mu \mathrm{L}$, BMEMs without BH loaded), and BH solution $\left(300 \mu \mathrm{L}, 2.8 \mathrm{mg} \cdot \mathrm{mL}^{-1}\right)$ were gently pipetted onto the CAM for 5 minutes, respectively. The samples were immediately washed by normal saline and $0.5 \mathrm{~mL}$ trypan blue solution $\left(1 \mathrm{mg} \cdot \mathrm{mL}^{-1}\right)$ was added on the CAM to stain for 1 minute. Finally, the dyed CAM was excised and the adsorbed trypan blue was extracted with $1 \mathrm{~mL}$ of formamide for 24 hours; the extract was measured spectrophotometrically at $611 \mathrm{~nm}$ in quintuplicate. $\mathrm{NaOH}(0.1 \mathrm{M})$ was used as a positive control and normal saline as a negative control. Any irritant reaction during the course of the experiments should be carefully observed, such as hyperemia, hemorrhage, clotting, and/or coagulation.

\section{In vitro preocular retention}

In this study, iHCECs were used to investigate the precorneal retention of BMEMs. As shown in Figure 2, after iHCECs became confluent, inert permeable polycarbonate inserts were lifted to the air-liquid interface to have a varying period of

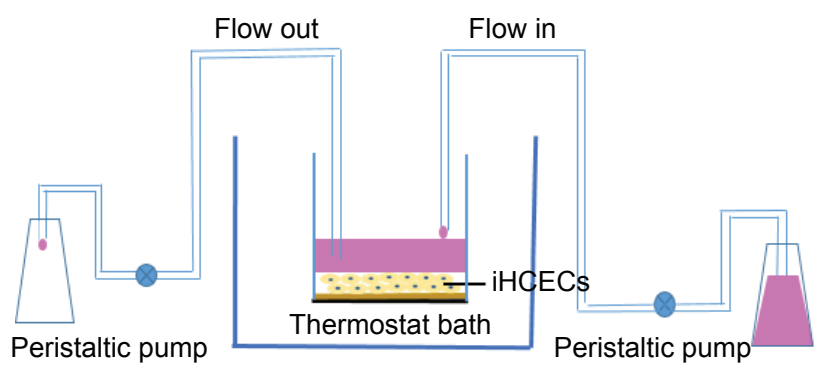

Figure 2 Schematic diagram of the in vitro tear turnover apparatus. The model incorporates an insert containing iHCECs as turnover chamber; the external basal side of the insert is sealed to avoid down diffusion of material. The temperature of the system is $34^{\circ} \mathrm{C}$ (the human tear film temperature). Two peristaltic pumps were used to control the inflow and outflow of simulated tears in the chamber. Abbreviation: iHCECs, human immortalized cornea epithelial cells. 
submerged cultivation (so-called reconstituted multilayer human corneal epithelia). The construct then appeared as a multilayered epithelium, which was histologically similar to that of the normal human corneal epithelium. ${ }^{34}$ Then, the insert was placed in a thermostat bath at $34^{\circ} \mathrm{C}$ (the temperature of the human tear film). The experiment was performed by transferring $30 \mu \mathrm{L}$ of sample $\left(2.8 \mathrm{mg} \cdot \mathrm{mL}^{-1}\right)$ in the turnover chamber prefilled with $270 \mu \mathrm{L}$ of simulated tear fluid, and the inflow and outflow of tears in the chamber were controlled by a peristaltic pump at the same speed $\left(20 \mu \mathrm{L} \cdot \mathrm{min}^{-1}\right)$. The above in vitro tear turnover model was used to simulate the drug concentration dynamics in the tear film. Finally, $200 \mu \mathrm{L}$ of solution was collected every 10 minutes, and the precorneal retention time was determined by HPLC-fluorescence detection.

\section{In vivo test \\ Draize test}

Rabbits were provided by the animal center of Guangdong Pharmaceutical University with a weight of $2.5-3.0 \mathrm{~kg}$ and without eye disease. They were housed in standard cages in a light-controlled room at $19^{\circ} \mathrm{C} \pm 1^{\circ} \mathrm{C}$, with food and water. All the animals were treated according to the Association for Research in Vision and Ophthalmology resolution for the use of animals in research and were approved for use by the Central Animal Ethical Committee of Guangdong Pharmaceutical University (approval number of the animal experiment protocols is gdpulac2017014). Both eyes were carefully checked before the experiments to ensure that they were without any defects.

The Draize test was used to evaluate the ocular irritation of normal saline, BH solution $\left(2.8 \mathrm{mg} \cdot \mathrm{mL}^{-1}\right)$, blank-BMEMs, and BMEMs $\left(2.8 \mathrm{mg} \cdot \mathrm{mL}^{-1}\right)$ by observing any signs of opacity, redness, inflammation, or increased tear production after application to the eyes of Albino rabbits. The single high-dosage ocular irritation test was conducted as follows. The left eyes of every group were treated with saline solution $(1 \mathrm{~mL})$ as control and the right eyes were subjected to a high dose of sample $(1 \mathrm{~mL})$ as the test group. The ocular tissue (cornea, iris, and conjunctiva) was examined at 1, 2, 4, 24, 48, and 72 hours after administration. The irritation was evaluated by "Draize eye test guideline." 35 In the multiple dosing ocular irritation tests, the left eyes of every group were treated with saline solution as control and the right eyes were subjected to $50 \mu \mathrm{L}$ of the sample $\left(2.8 \mathrm{mg} \cdot \mathrm{mL}^{-1}\right)$ twice a day for 7 days. After the irritation test, these rabbits were sacrificed by intravenous injection of air. Then, the eyeballs were excised for observation of cornea tissues' morphology: cornea tissue treated with $10 \%$ formalin for 24 hours, embedded in paraffin, making a pathological section, stained with hematoxylin and eosin, and observed by a light microscope. ${ }^{36}$

\section{In vivo preocular retention}

The ability of precorneal retention was evaluated by tears elimination. The animals used for the experiments were New Zealand White rabbits. Rabbits, in spite of having a nictitating membrane and very low blinking frequency, are generally considered as the reference animal for ocular experiments due to several similarities between the anatomy of the rabbit and the human eye. ${ }^{31}$ Briefly, the rabbits were given an instillation of $100 \mu \mathrm{L}$ of formulations $\left(2.8 \mathrm{mg} \cdot \mathrm{mL}^{-1}\right)$ in the lower conjunctival sac of each cornea and kept the eyelids closed for 5 seconds to prevent loss of the instilled solution. After drug instillation, tear samples were collected by using $8 \times 8 \mathrm{~mm}$ filter paper at 10 , $30,60,90,120,180$, and 240 minutes. The filter paper with tear was stored in microcentrifuge tubes and the weight of the collected tear was recorded. Then, the collected sample was dried by nitrogen flow and $200 \mu \mathrm{L}$ of methanol solvent was added to dissolve it. Finally, the samples were centrifuged for 30 minutes. Quantitation was performed by HPLC assays.

\section{Pharmacodynamics}

After 1 week of adaptation in the facilities, the eyes of all animals were examined with a slit lamp to exclude any disease that could interfere with the experimental results. IOP (mmHg) was measured using an indentation tonometer (YZ7A; Suzhou Visual Technology Co, Ltd, Suzhou, China). The high-IOP model rabbits were induced by gavage with high dose of saline. ${ }^{37}$ The right eye conjunctival sac of the high-IOP model rabbit was administered $100 \mu \mathrm{L}$ of sample $\left(2.8 \mathrm{mg} \cdot \mathrm{mL}^{-1}\right)$ and the left eye was treated with physiological saline as the control group. After the application of samples, IOP determination was carried out at $0,15,30,45,60,90$, $120,180,240,300$, and 360 minutes. All the measurements were done six times at each interval by the same operator under the same environmental conditions.

\section{Statistical analysis}

Statistical analysis of the results was performed using oneway analysis of variances, referring to a level of $p<0.05$. The analysis was computed using Origin 8 software (OriginLab company, Hampton, MA, USA).

\section{Results and discussion Preparation \\ Acidification and DL of Mt}

After acid treatment, the interlayer cation of Mt was replaced by $\mathrm{H}^{+}$. This process resulted in an increased layer spacing and 

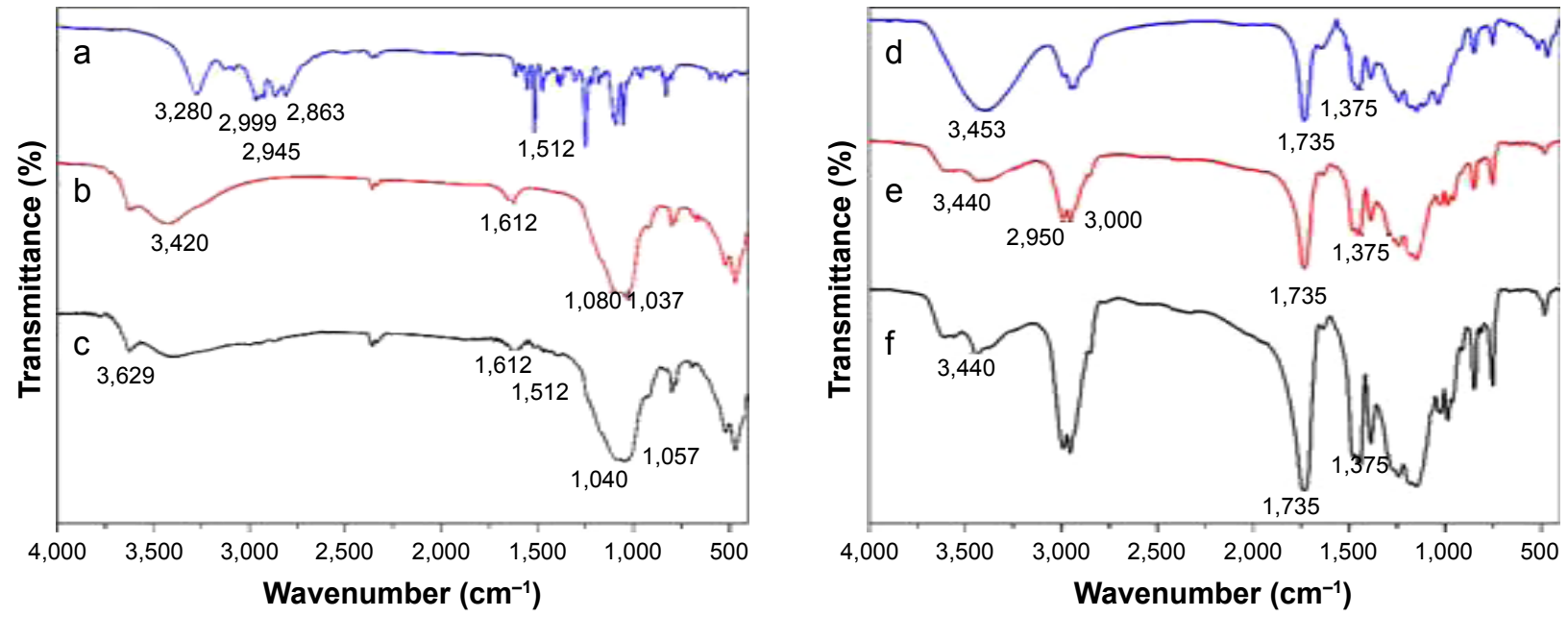

Figure 3 The FTIR spectrum of (a) BH, (b) acid-Mt, (c) Mt-BH, (d) BMEM, (e) Eudragit RLI00, and (f) Eudragit RSI00.

Abbreviations: Acid-Mt, montmorillonite treated with acid; $\mathrm{BH}$, betaxolol hydrochloride; BMEM, betaxolol hydrochloride encapsulated microsphere; FTIR, Fourier transform infrared; Mt, montmorillonite; $\mathrm{Mt}-\mathrm{BH}$, betaxolol hydrochloride loaded into montmorillonite.

CEC of the products. In this study, the effect of concentration of sulfuric acid $(\mathrm{V} / \mathrm{V})$, solid-to-liquid ratio $(\mathrm{mg} / \mathrm{mL})$, treatment temperature, and time were investigated on the structural properties and on the $\mathrm{BH}$ intercalation feature of Mt. Optimal acid treatment of Mt was done by using a solid-to-liquid ratio of 1:10 (Mt:5\% sulfuric acid, $\mathrm{mg} / \mathrm{V})$ at $70^{\circ} \mathrm{C}$ for 0.5 hours. The optimal intercalation of acid-Mt with $\mathrm{BH}$ was as follows: a mass ratio of 1:3 (acid-Mt:BH) was dissolved in deionized water and heated at $50^{\circ} \mathrm{C}$ for intercalation of $\mathrm{BH}$ into acid-Mt. The result showed that maximum loading rates of $\mathrm{Mt}$ increased from 153.6 \pm 7.6 to $474.52 \pm 5.4 \mathrm{mg} \cdot \mathrm{g}^{-1}(\mathrm{n}=5)$ after acid treatment. This increase in DL after acid treatment can be attributed to both the increased basal spacing and increased ion-exchange reaction..$^{38}$ This is in good agreement with the result of XRD and FTIR (Figures 3 and 4).

\section{Preparation of BMEMs}

There are many factors that influenced the structure and property of BMEMs, including starting materials, reactants ratio, and temperature. For example, Eudragit RS100, as a microsphere skeleton material, possesses a typical low burst effect, while the hypertonicity of Eudragit RL100 contributes to the complete release of drug. Therefore, the combination of Eudragit RS100 with Eudragit RL100 has generated a great deal of interest to obtain microspheres, possessing a structure with low burst effect and complete release feature. ${ }^{39-41}$ In this study, the Mt-BH:Eudragit RL/RS 100 ratios in the range of $1: 4$ to $1: 8$ contributed to the spherical morphology of the particles with fine size and high encapsulation efficiency $(>80 \%)$. Temperature was another important parameter, which affected mainly the emulsification and evaporation process. Emulsification with an ice bath led to well-distributed droplets which were beneficial to form uniform microspheres with a significantly lower burst effect and improved sustained release. Furthermore, the evaporation temperature also showed a great effect on the $\mathrm{EE} \%$ and DL\% of microspheres. The EE\% and DL\% values of microspheres evaporated at the ice bath, RT and $30^{\circ} \mathrm{C}-40^{\circ} \mathrm{C}$ were $66.26 \%, 90.1 \%, 74.5 \%$, and $7.62 \%, 10.82 \%, 8.94 \%$, respectively. Hence, the ice bath and RT were chosen for the emulsification reaction and evaporation of organic solvent, respectively.

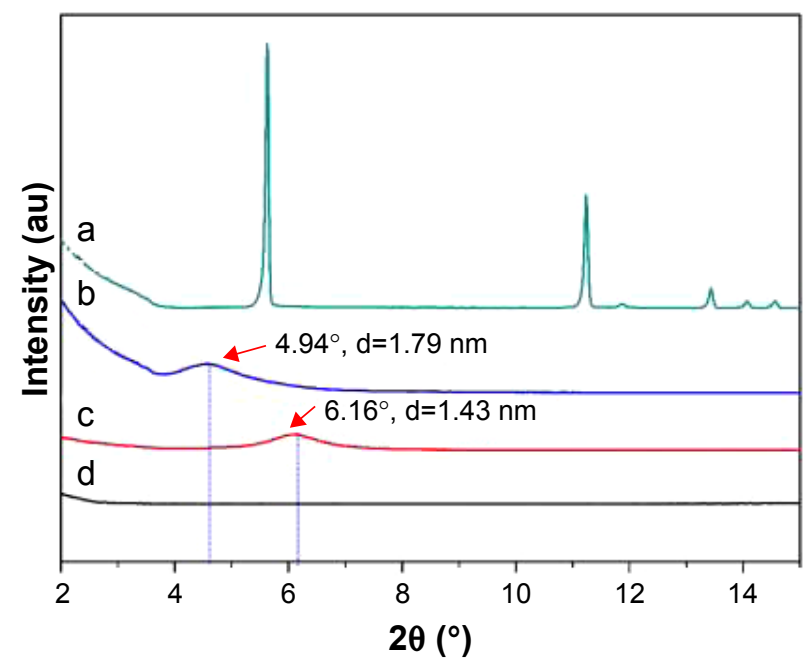

Figure 4 The XRD patterns of (a) BH, (b) Mt-BH, (c) acid-Mt, and (d) BMEM. Abbreviations: Acid-Mt, montmorillonite treated with acid; Mt, montmorillonite; $\mathrm{BH}$, betaxolol hydrochloride; $\mathrm{Mt}-\mathrm{BH}$, betaxolol hydrochloride loaded into montmorillonite; BMEM, betaxolol hydrochloride encapsulated microsphere; XRD, X-ray diffraction. 
The EE $\%$ and DL $\%$ of BMEMs were $94.35 \% \pm 1.01 \%$ and $14.31 \% \pm 0.47 \%(n=5)$, respectively, which indicated that the method was reproducible and stable. Mt-BH could serve as a co-emulsifier in the preparation process, which increased the stability of the emulsions and showed little effect on $\mathrm{EE} \%$ and $\mathrm{DL} \%{ }^{42}$

\section{FTIR, XRD, and SEM studies of samples}

The FTIR spectrum of BH (Figure 3a) showed characteristic absorptions at 3,280,3,000-2,800, and 1,512 $\mathrm{cm}^{-1}$, corresponding to the $-\mathrm{OH}$ stretching, alkyl chain $\mathrm{C}-\mathrm{H}$ stretching, and aromatic ring $\mathrm{C}-\mathrm{H}$ deformation vibrations, respectively. The infrared spectrum of acid-Mt (Figure 3b) showed absorptions at 3,420,1,080, and $1,037 \mathrm{~cm}^{-1}$ due to the $-\mathrm{OH}$ stretching of adsorbed water, $\mathrm{Si}-\mathrm{O}$ out-of-plane, and in-plane stretching vibrations of $\mathrm{Mt}$, respectively. ${ }^{29}$ After the loading of $\mathrm{BH}$, the products showed a group of new absorptions at 3,000-2,800 and 1,512 $\mathrm{cm}^{-1}$ (Figure 3c), which were attributed to the alkyl chain $\mathrm{C}-\mathrm{H}$ stretching and aromatic ring $\mathrm{C}-\mathrm{H}$ deformation vibrations, respectively. Compared with the absorption bands of $\mathrm{BH}$, the absorption bands of $\mathrm{BH}$ from Mt-BH showed small band shifts and intensity reductions (or disappeared) in the wavenumber region of 3,280-2,800 $\mathrm{cm}^{-1}$. These changes suggested that intercalation of $\mathrm{BH}$ into Mt was successful and both physical and chemical interactions existed between loaded $\mathrm{BH}$ and acid-Mt. The FTIR spectra of Eudragit RL/RS 100 are showed in Figure 3e and $\mathrm{f}$. The peak at 2,950-3,000, 1,375, 1,735 , and $3,440 \mathrm{~cm}^{-1}$ can be assigned to $\mathrm{O}-\mathrm{H},-\mathrm{CH}_{3}, \mathrm{C}=\mathrm{O}$, and free $\mathrm{OH}$ stretching, respectively. This indicates a typical vibration mode of Eudragit RL/RS 100. For the FTIR of BMEMs, all the characteristic bands of acid-Mt cannot be distinguished in the spectrum of BMEMs, including the surface-OH stretching of acid-Mt at 3,629 $\mathrm{cm}^{-1}$, water bending at $1,612 \mathrm{~cm}^{-1}$, and $\mathrm{Si}-\mathrm{O}$ related stretching at $1,100 \mathrm{~cm}^{-1}$. Meanwhile, some peaks appeared at 3,440 $\mathrm{cm}^{-1}$ (free $\mathrm{OH}), 2,950-3,000 \mathrm{~cm}^{-1}(\mathrm{O}-\mathrm{H}), 1,375 \mathrm{~cm}^{-1}\left(-\mathrm{CH}_{3}\right)$, and $1,735 \mathrm{~cm}^{-1}(\mathrm{C}=\mathrm{O})$, which confirmed the formation of BMEMs from Eudragit RL/RS 100.

As shown in the XRD patterns (Figure 4), the XRD peaks for the $\mathrm{BH}$ pure powder are relatively sharp, which showed that $\mathrm{BH}$ was in its perfect crystalline form. Reflections for the $(001)$ plane of acid-Mt and Mt-BH were observed at $2 \theta=6.2^{\circ}$ and $4.9^{\circ}$, respectively. The calculated $\mathrm{d}_{001}$ values of acid-Mt and Mt-BH were 1.43 and $1.79 \mathrm{~nm}$, respectively. The increase in $\mathrm{d}$ value resulted from the intercalation of $\mathrm{BH}$ into the interlayer space of Mt. Furthermore, the XRD results (Figure 4) showed that the characteristic reflections of acid-Mt and Mt-BH disappeared as shown in the BMEM pattern. All the above-mentioned changes implied that Mt-BH was successfully encapsulated into the microspheres and BMEM was successfully formed.

Both SEM images of Mt and acid-Mt showed irregular layer particles and randomly orientated aggregations (Figure 5A and B), which are characteristic morphologies of natural clays and acid-treated clays. ${ }^{43}$ Intercalation of $\mathrm{BH}$ apparently led to a smoother surface of the particles as observed from Mt-BH (Figure 5C). Both conventional BH
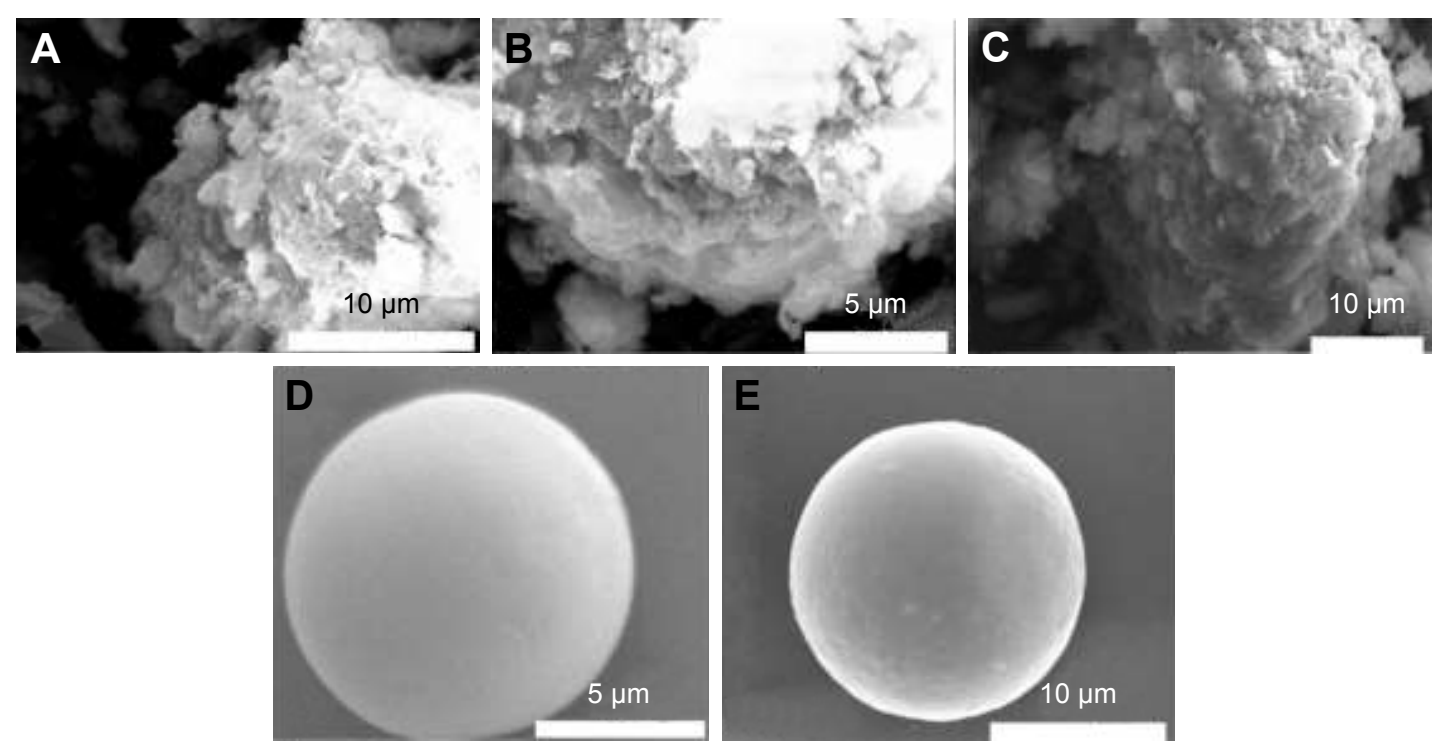

Figure 5 The SEM images of (A) raw Mt, (B) acid-Mt, (C) Mt-BH, (D) conventional microsphere, and (E) BMEM.

Abbreviations: Acid-Mt, montmorillonite treated with acid; BMEM, betaxolol hydrochloride encapsulated microsphere; Mt, montmorillonite; Mt-BH, betaxolol hydrochloride loaded into montmorillonite; SEM, scanning electron microscopy. 
microspheres (absence of Mt) and BMEMs showed spherical morphologies (Figure 5D and E), and the latter was relatively rough in surface, due to the encapsulation of Mt-BH.

\section{In vitro release studies}

The burst release would cause many adverse reactions due to the sharp increase of drug concentration. As shown in Figure $6 \mathrm{a}$, the $\mathrm{BH}$ solution exhibited a rapid release in artificial tears (over 90\% in the initial 1 hour and almost $100 \%$ within 2.5 hours). Conventional BH microspheres (absence of $\mathrm{Mt}$ ) could reduce such a burst at limited extent and prolong the release duration to 5 hours (Figure 6b). As for BMEMs, the release duration can be extended to 12 hours. And the whole release process included four stages (Figure 6c). For the first stage, $\mathrm{BH}$ absorbed on the surface of microspheres was released (Figures 6c-1 and 7). Second, the BH encapsulated in the microsphere matrix but not intercalated into the Mt layer was released (Figures 6c-2 and 7). Third, the BH intercalated into the Mt layer was released into the inner region of the microsphere matrix (Figures 6c-3 and 7). Fourth, BH from the microspheres was released into the medium (Figures $6 c-4$ and 7). At the first burst process, the drug released sharply from the surface of BMEMs with an initial release rate of $37.58 \%$ (2.5 hours) and from conventional microspheres at a rate of $46.14 \%$ at 2.5 hours, which is potentially beneficial to producing a therapeutic concentration. ${ }^{44}$ The significant induction of the initial release rate can be attributed to relatively more drug molecules being encapsulated into the microsphere than conventional microspheres. Also, only a few drugs were adsorbed to the surface of the microsphere, so the proportion of the release of the drug at the first burst process was low. For conventional microspheres (Figure 6b),

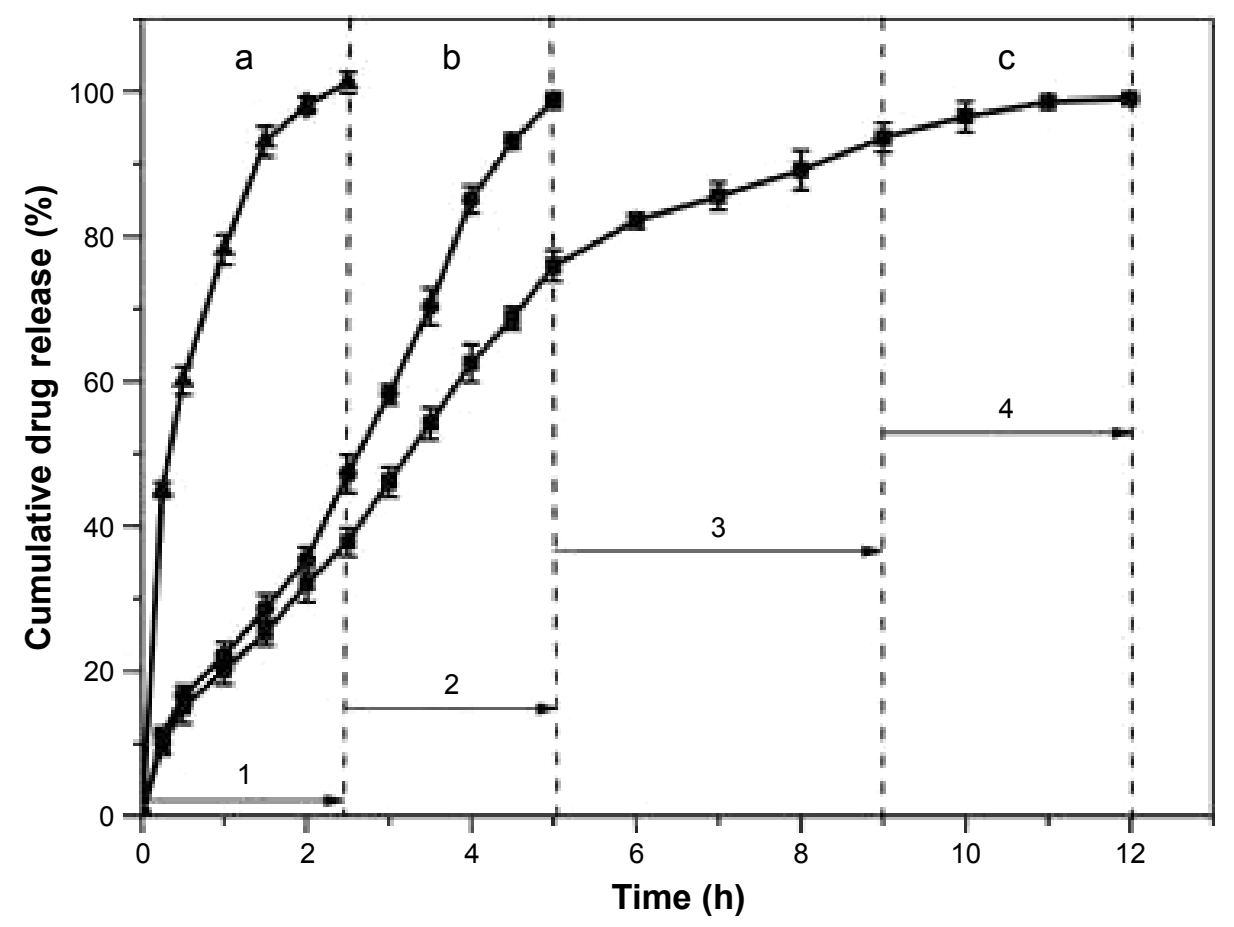

A

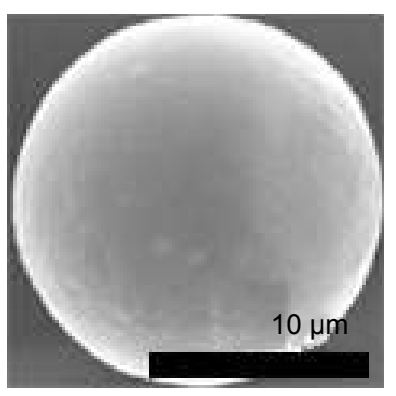

B

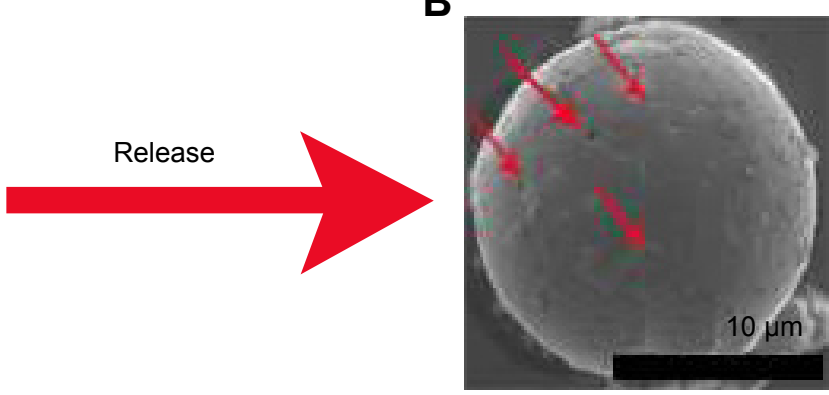

Figure 6 In vitro dialysis release study of $\mathrm{BH}$ from formulations: (a) BH solution, (b) conventional BH microsphere, and (c) BMEM. The cumulative drug release (\%) is plotted against time $(h)$. Values are presented as the mean \pm SD $(n=5)$. SEM micrographs of BMEM: $(\mathbf{A})$ microsphere before release process and $(\mathbf{B})$ microsphere after release process.

Abbreviations: $\mathrm{BH}$, betaxolol hydrochloride; BMEM, betaxolol hydrochloride encapsulated microsphere; SEM, scanning electron microscopy. 


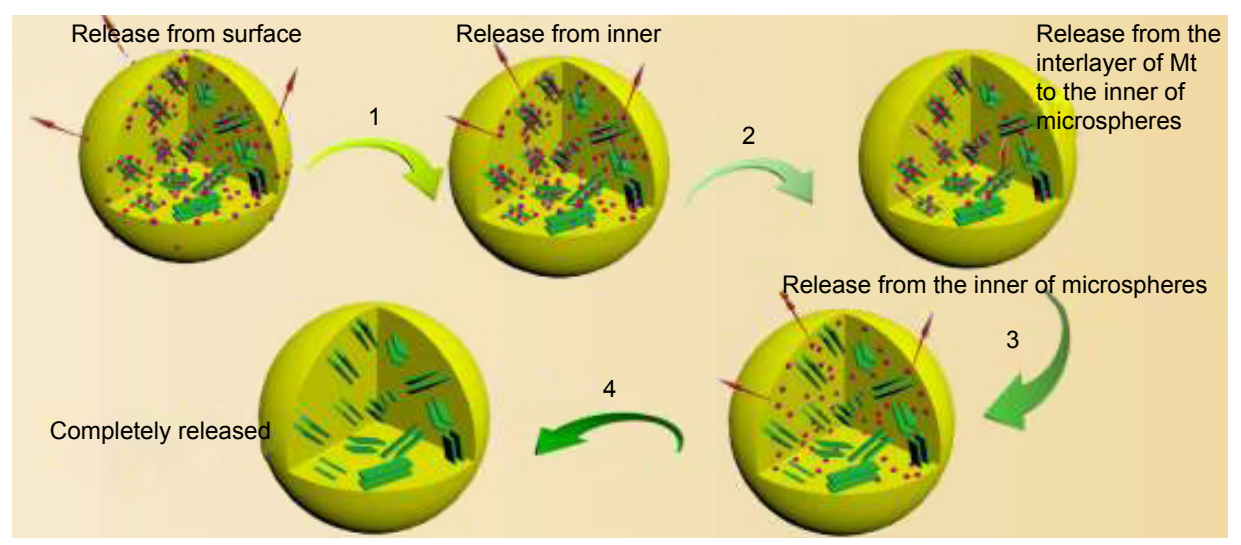

Figure $7 \mathrm{In}$ vitro release processes of BMEM. The whole release of BMEM could be divided into 4 stages, including the release of $\mathrm{BH}$ (I) absorbed on the surface of the microsphere, (2) encapsulated in the microsphere matrix but not intercalated into the Mt layer, (3) absorbed on the surface of Mt, and (4) intercalated in Mt. Abbreviations: $\mathrm{BH}$, betaxolol hydrochloride; BMEM, betaxolol hydrochloride encapsulated microsphere; Mt, montmorillonite.

the drug was completely released from the conventional microspheres within 5 hours, while that of BMEMs was nearly $76 \%$ at 5 hours. Besides, BMEMs also exhibited a unique drug release process in the duration of $5-9$ hours with a cumulative release of $98.8 \%$ at 12 hours, due to the characteristics of high ion exchange of Mt in the drug release process. Therefore, BH release from BMEMs was significantly prolonged after encapsulation of Mt-BH. The drug release process showed that the in vitro drug release profile of BMEMs was consistent with first-order kinetics (Log $(100-Y)=2.071-0.134 \mathrm{t}, r=0.9915)$. This indicated that the $\mathrm{BH}$ release from BMEMs was controlled by diffusion.

In addition, Figure $6 \mathrm{~A}$ and $\mathrm{B}$ shows the morphology of BMEMs after release duration. It is clearly seen that the general morphology of BMEMs after release duration had no significant difference with that of before release duration. Interestingly, some of the holes on the surface of BMEMs were clearly seen in Figure 6B. It could be predicted that the medicine molecules released slowly from BMEMs through diffusion from those holes without dissolution and/or degradation of microspheres.

\section{Cytotoxicity study}

It is well known that a promising microparticle system used for ocular purposes must demonstrate ocular tolerability. In this study, ocular irritation of the developed formulation was directly measured using the MTT test to evaluate the cytotoxicity on iHCECs. MTT can be oxidized by the mitochondrial dehydrogenase in living cells to obtain a dark blue formazan product. The cell survival rate was $<50 \%$, which indicates that mitochondrial activity was reduced. ${ }^{40} \mathrm{iHCECs}$ were exposed to BH solution, blank-BMEMs, and BMEMs at different concentrations for 120 minutes (Figure 8). In three formulations, the cell viability decreased with increase of drug concentration. For BH solution, the cell viability was above $60 \%$ when the drug concentration was $<0.84 \mathrm{mg} \cdot \mathrm{mL}^{-1}$. However, when the drug concentration was $>1.4 \mathrm{mg} \cdot \mathrm{mL}^{-1}$, the cell survival rate fell to $<5 \%$, which showed that $\mathrm{BH}$ had a toxic effect on iHCECs in higher concentration levels. In comparison with the BH solution, for the cell viability of iHCECs treated with blank-BMEMs and BMEMs at low level $\left(<0.84 \mathrm{mg} \cdot \mathrm{mL}^{-1}\right)$, the cell survival rate was very high, but at high values $\left(>1.4 \mathrm{mg} \cdot \mathrm{mL}^{-1}\right)$, the cell survival rates of blank-BMEMs and BMEMs were significantly higher than that of the BH solution. Meanwhile, it could be found that the cell viability of iHCEC cells treated with blank-BMEMs

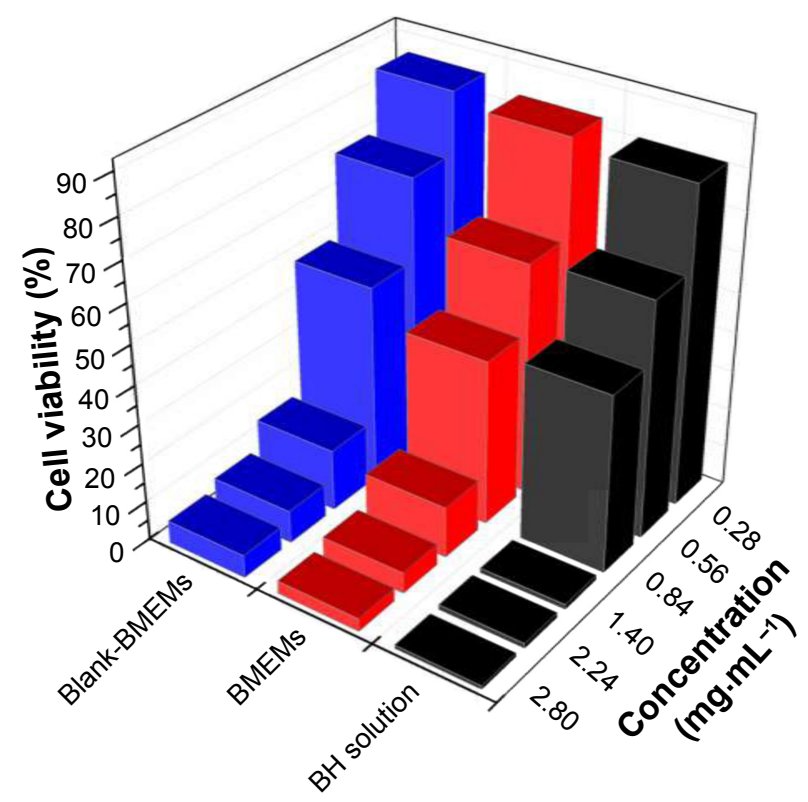

Figure 8 Cell viability (\%) of iHCECs determined by MTT assay after exposing them to different concentrations $\left(0.28,0.56,0.84,1.40,2.24\right.$, and $\left.2.8 \mathrm{mg} \cdot \mathrm{mL}^{-1}\right)$ of $\mathrm{BH}$ solution, blank-BMEM, and BMEM for 120 minutes.

Abbreviations: $\mathrm{BH}$, betaxolol hydrochloride; BMEM, betaxolol hydrochloride encapsulated microsphere; iHCECs, human immortalized cornea epithelial cells. 
was higher than BMEMs at the same amounts. This may be explained by the fact that microspheres could protect the cells from damage by $\mathrm{BH}$ (raw drug). Each sample of cytotoxicity was in such a sequence: $\mathrm{BH}$ solution $>$ BMEMs $>$ blank-BMEMs. From these results, it is clearly obvious that BMEMs could effectively maintain superior cell viability within an appropriate range.

\section{CAM-TBS}

CAM-TBS test is an alternative toxicological method widely used to determine ocular irritation potential. ${ }^{41}$ The CAM is a highly vascular embryonic membrane and stratified tissue, which can respond to injury in a similar manner as mucosal and subcutaneous tissue. It might provide very useful information for predicting the potential eye irritation caused by a substance. The irritant effect of these substances is determined by the amount of trypan blue absorption of CAM. It is very simple and reproducible, as well as quantitative. ${ }^{45}$ Figure 9 shows the trypan blue absorption onto the CAM after exposure to BMEMs, BH solution, blank-BMEMs, saline solution, and $\mathrm{NaOH}$. It is clear that each sample followed this sequence for cytotoxicity: $\mathrm{NaOH}>\mathrm{BH}$ solution $>$ BMEMs $>$ blank-BMEMs $>$ saline solution. These results revealed that BMEMs had less irritation for ocular drug delivery compared with BH solution.

\section{In vitro preocular retention}

Cell culture models of ocular barriers offer the advantage of highly defined, compliant systems to investigate drug behavior, bio-adhesion characteristics, and pharmacokinetic

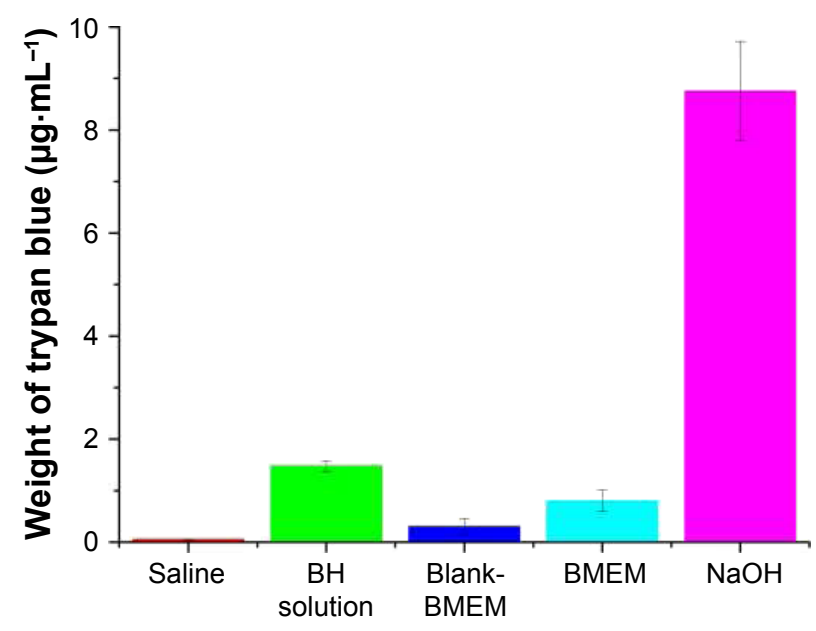

Figure 9 Eye irritancy induced by different concentrations of $\mathrm{BH}$ solution, blankBMEM, and BMEM determined by the in vitro CAM-TBS method. $\mathrm{NaOH}$ was used as a positive control and normal saline as a negative control. Values are presented as the mean $\pm S D(n=5)$.

Abbreviations: $\mathrm{BH}$, betaxolol hydrochloride; BMEM, betaxolol hydrochloride encapsulated microsphere; CAM, chorioallantoic membrane; TBS, trypan blue staining. properties of medicine preparation. The experimental parameters and conditions can be easily adjusted according to our requirements, and cultured human cells have good correlations with in vivo behavior to some extent, thereby avoiding species difference and the use of animal tissue. Histologically, cell culture models of ocular barriers resemble the normal human corneal epithelium, which can provide powerful systems to investigate the residence of a drug in the precorneal area. The concentration of $\mathrm{BH}$ in cornea/tear film compartment as a function of time was monitored after administration of $\mathrm{BH}$ solution and BMEMs (Figure 10). For the $\mathrm{BH}$ solution, the $\mathrm{BH}$ concentration in tears rapidly fell from about 65.45 down to $6.33 \mu \mathrm{g} \cdot \mathrm{mL}^{-1}$ only within 40 minutes. Although the $C_{\max }$ of $\mathrm{BH}$ solution was significantly higher than BMEMs, it could remain in the precorneal position for a short time, only just 80 minutes. BMEMs decreased from about 50.25 down to $9.33 \mu \mathrm{g} \cdot \mathrm{mL}^{-1}$ during the period of 50 minutes (which is 1.5 -fold compared to the $\mathrm{BH}$ solution at 50 minutes). Meanwhile, BMEMs could still be detected at 120 minutes, which may explain the sustained release of BMEMs. These results revealed that $\mathrm{BH}$ could release from BMEMs slowly over time and maintained a certain $\mathrm{BH}$ concentration in tear fluid for a prolonged period of time.

\section{In vivo test}

\section{Draize test}

Eye safety is of crucial importance to be evaluated to avoid damage to the ocular tissues due to the sensitive nature of the eye. The experiment was implemented by using rabbits as a

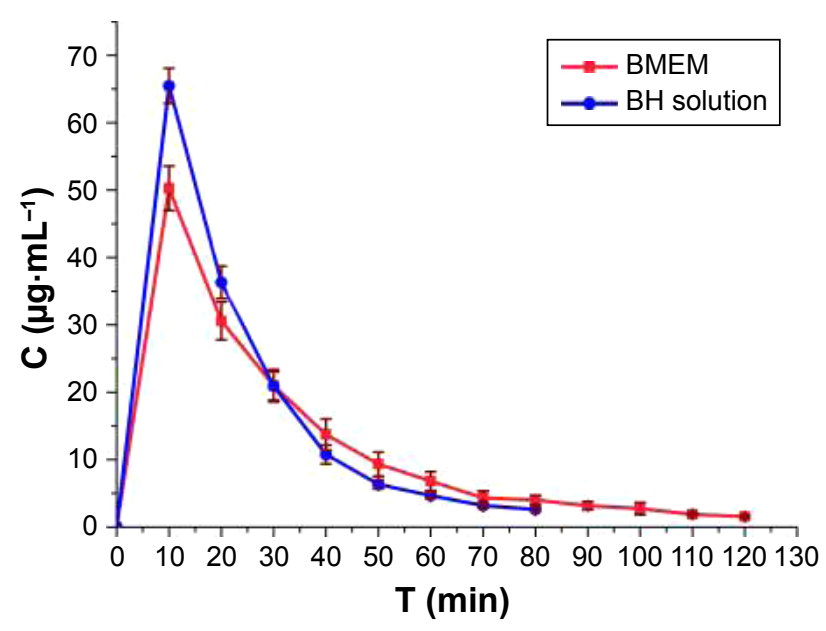

Figure 10 Concentration-time curve in the cornea/tear film compartment after the instillation of $\mathrm{BH}$ solution $\left(2.8 \mathrm{mg} \cdot \mathrm{mL}^{-1}\right)$ and BMEM $\left(2.8 \mathrm{mg} \cdot \mathrm{mL}^{-1}\right)$. Values are presented as the mean \pm SD $(n=5)$.

Abbreviations: $\mathrm{BH}$, betaxolol hydrochloride; BMEM, betaxolol hydrochloride encapsulated microsphere. 
Table I Draize test scores after single and multiple dose formulations: saline, BH solution, blank-BMEMs, and BMEMs ( $\mathrm{n}=5$ )

\begin{tabular}{|c|c|c|c|c|c|c|c|c|c|}
\hline \multirow[t]{2}{*}{ Symptom } & \multicolumn{2}{|c|}{ Normal saline } & \multicolumn{2}{|c|}{ Blank-BMEM } & \multicolumn{2}{|l|}{ BMEM } & \multicolumn{2}{|c|}{ BH solution } & \multirow[t]{2}{*}{ Normal } \\
\hline & Single & Multiple & Single & Multiple & Single & Multiple & Single & Multiple & \\
\hline Cornea & 0 & 0 & 0 & 0 & 0 & 0 & 0 & 0 & 0 \\
\hline Iris & 0 & 0 & 0 & 0 & 0 & 0 & 0 & 0.3 & 0 \\
\hline Conjunctiva congestion & 1 & 0.8 & 0 & 0.2 & 1 & I & 1 & 1 & 0.2 \\
\hline Conjunctive edema & 0 & 0 & 0 & 0 & 0 & 0 & 0 & 0.3 & 0 \\
\hline Secretions & 0 & 0 & 0 & 0 & 0 & 0 & 0 & 0.3 & 0 \\
\hline Score & I & 0.8 & 0 & 0.2 & 1 & I & 1 & 2 & 0.2 \\
\hline
\end{tabular}

Abbreviations: $\mathrm{BH}$, betaxolol hydrochloride; BMEM, betaxolol hydrochloride encapsulated microsphere.

model due to their large eyes with well-described anatomy and physiology. However, the eyes of rabbits are generally more sensitive to irritating materials than the humans' eyes. ${ }^{43}$ From the results of Draize study (Table 1), it was found that all groups appeared to have a slight congestion status in conjunctiva including the normal saline group (control group), which might be attributed to the high sensitivity to external structure materials. However, the Draize test revealed that the total score for all the rabbits were less than all three scores, which indicated that all samples had no significant damage to ocular tissues. Furthermore, cornea histological experiment was carried out for a more accurate evaluation of the safety of BMEMs on the eye. The histological analysis of corneal sections after the high-dose irritation test are shown in Figure 11. The normal cornea tissue showed a smooth surface and a clear organizational structure of layers (Figure 11A). Corneal tissue had no obvious pathological changes after administration of normal saline (Figure 11B). However, after treatment with $\mathrm{BH}$ solution, the corneal epithelial cells showed mild edema with some abnormal cells (Figure 11C). As shown in Figure 11D and E, the corneal epithelial cells exhibited a handful of edema cells after the multiple dosing of BMEMs and blank-BMEMs. Figure $11 \mathrm{~F}$ and $\mathrm{G}$ showed no significant pathological changes after administration of a single dose of BMEMs and blank-BMEMs. The histological analysis demonstrated that BMEMs had very little irritation for the cornea, which was consistent with the results of the cytotoxicity study and CAM-TBS. Based on these findings, it was confirmed that BMEMs were safer and less toxic to the eye than $\mathrm{BH}$ solution for ophthalmic administration.

\section{In vivo preocular retention}

It was estimated that about $80 \%$ of the topically administered eye drops were drained through the nasolacrimal duct, with high tear fluid turnover, and systemically absorbed. ${ }^{46}$ Only $<5 \%$ of the applied drug could penetrate the cornea and reach the intraocular tissues, resulting in low ocular bioavailability. The precorneal retention time is shown after the application of BH solution and BMEMs (Figure 12). It is obvious that the $\mathrm{BH}$ solution was quickly removed by tear fluid turnover, and the concentration of the BH solution was only $478.44 \mu \mathrm{g} \cdot \mathrm{mL}^{-1}$ after the administration of 10 minutes, which can explain the low viscosity of the aqueous solution and strong stimulation. It is worth noting that
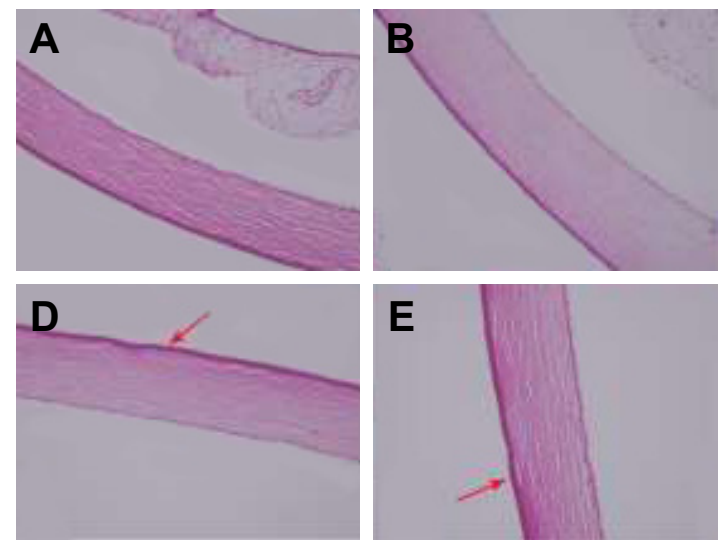
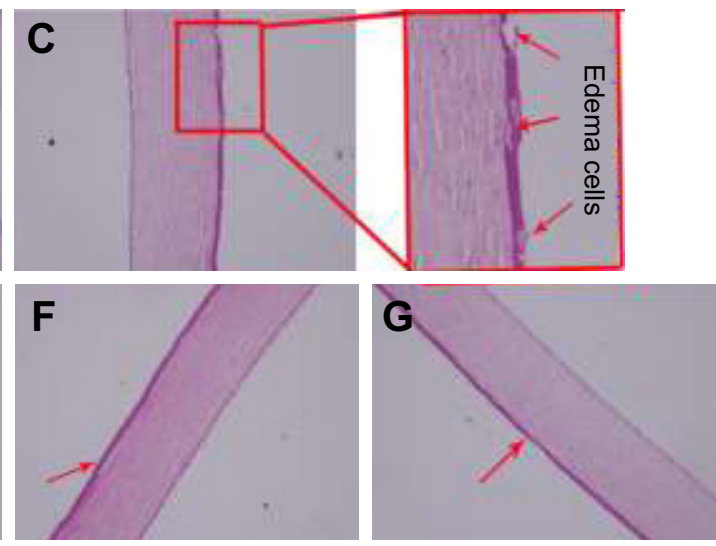

Figure I I Cornea histopathology analysis after the high-dose irritation test by microscopy. (A) Normal cornea, (B) saline, (C) BH solution, (D) a single high dose of blankBMEM, (E) a single high dose of BMEM, (F) multiple dose of blank-BMEM, and (G) multiple dose of BMEM.

Abbreviations: $\mathrm{BH}$, betaxolol hydrochloride; BMEM, betaxolol hydrochloride encapsulated microsphere. 


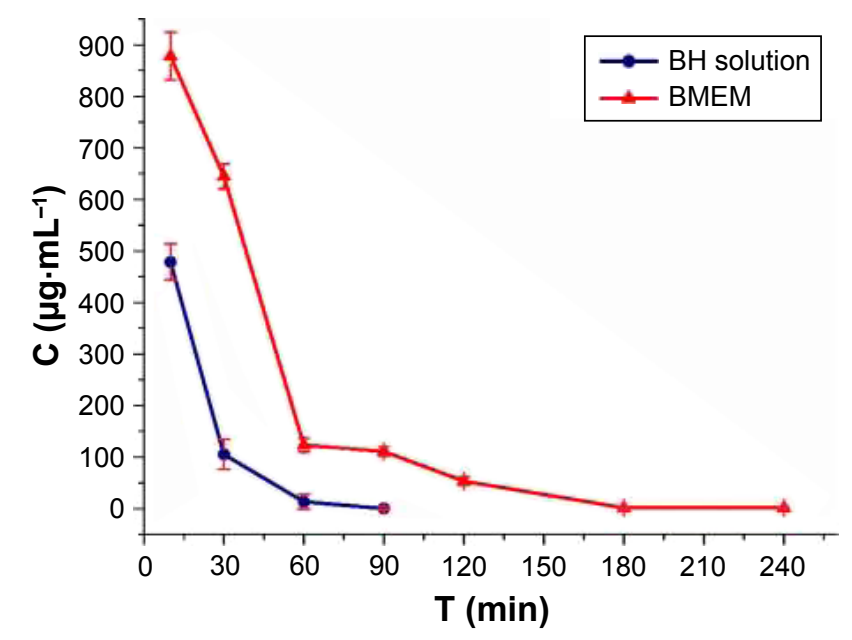

Figure 12 The tear fluid concentration-time curve after topical application of $\mathrm{BH}$ solution $\left(2.8 \mathrm{mg} \cdot \mathrm{mL}^{-1}\right)$ and BMEM $\left(2.8 \mathrm{mg} \cdot \mathrm{mL}^{-1}\right)$ in rabbit eyes. Values are presented as the mean $\pm S D(n=5)$.

Abbreviations: $\mathrm{BH}$, betaxolol hydrochloride; BMEM, betaxolol hydrochloride encapsulated microsphere.

the drug concentration of $\mathrm{BH}$ solution cannot be observed after 90 minutes, since it was below the detection limit of HPLC. BMEMs could still maintain drug concentration after $>240$ minutes. BMEM was composed of polyacrylic acid, which was a mucoadhesive polymer. These mucoadhesive polymers could interact with the precorneal mucin layer via noncovalent bonds. Thus, it could increase the residence time of the drug on the ocular surface, decrease drug loss, and eventually improve bioavailability. These results illustrated that BMEMs could be of value as a vehicle for ocular applications due to the reduction of precorneal loss caused by drainage and high tear fluid turnover.

\section{Pharmacodynamics}

As shown in Figure 13, two formulations could significantly reduce the high IOP to some extent. BH solution attained the maximum effect $(5.04 \mathrm{mmHg})$ of lowering IOP after administration for 30 minutes and the IOP significantly declined after administration for 60 minutes. BMEMs have a sustained IOP-lowering effect and attained the maximum effect $(4.89 \mathrm{mmHg})$ of lowering IOP after 120-minute administration. In comparison with the $\mathrm{BH}$ solution, BMEMs could maintain a longer effect of lowering IOP than that of the BH solution. This could be because BMEMs could stay on the preocular surface to some extent and simultaneously release the drug in a sustained manner. Therefore, the IOPlowering effect was continuous, steady, and would avoid many side effects caused the sharp reduction of IOP. ${ }^{47-49}$ These results suggested that BMEMs had a sustained IOPlowering effect.

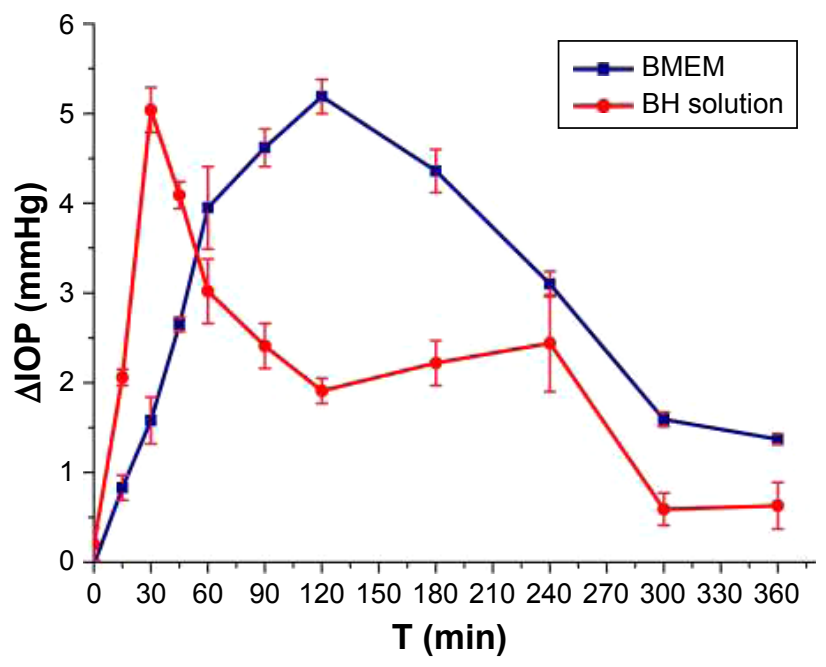

Figure 13 Effect on IOP changes induced by a single topical instillation of BMEM $\left(2.8 \mathrm{mg} \cdot \mathrm{mL}^{-1}\right)$ in rabbit eyes in comparison with $\mathrm{BH}$ solution $\left(2.8 \mathrm{mg} \cdot \mathrm{mL}^{-1}\right)$. Values are presented as the mean $\pm S D(n=6)$.

Abbreviations: $\mathrm{BH}$, betaxolol hydrochloride; BMEM, betaxolol hydrochloride encapsulated microsphere; IOP, intraocular pressure.

\section{Conclusion}

A new controlled drug delivery carrier (BMEM) for glaucoma therapy was successfully prepared by a combination of acidification-intercalation and $\mathrm{O} / \mathrm{O}$ emulsion-solvent evaporation method. This carrier was composed of bioadhesive materials and demonstrated the ion-exchange ability of Mt. With the acid treatment, the Q of Mt was significantly increased from $153.6 \pm 7.6$ to $474.52 \pm 5.4 \mathrm{mg} \cdot \mathrm{g}^{-1}$. Both FTIR and XRD measurements proved that BH was successfully intercalated into acid-Mt. SEM images showed that BMEMs were rougher and slightly larger than conventional $\mathrm{BH}$ microspheres, due to the encapsulation of Mt-BH. BMEMs exhibited the longest sustained release duration (12 hours) in comparison with the BH solution (2.5 hours) and conventional $\mathrm{BH}$ microspheres (5 hours), since the incorporation of $\mathrm{Mt}-\mathrm{BH}$ has prolonged the release time of $\mathrm{BH}$ by ion exchange. We hypothesized that the in vitro release process may have four stages (last for 12 hours) that caused the BH to be slowly released. The MTT test, CAMTBS, and Draize test have shown higher security than BH solution. In vitro and in vivo precorneal retention have also shown that BMEMs have a prolonged retention time because BMEMs have intimate contact with the epithelial mucosal surface of the eye to prevent tear washout. It is noteworthy that BMEMs present a strong effect on reducing the high IOP. Taken together, BMEMs presented extended release, prolonged precorneal retention time, and better tolerability at the corneal site, which would have potential applications in glaucoma treatment. 


\section{Acknowledgments}

This work was financially supported by the National Natural Science Foundation of China (grant no 51102052), Medical Scientific Research Foundation of Guangdong Province (grant no A2016275), and a collaborative project from Science and Technology Planning Project of Guangdong Province, China (2017B030314175). iHCEC was kindly provided by Shandong Eye Institute (Qingdao, China).

\section{Disclosure}

The authors report no conflicts of interest in this work.

\section{References}

1. Quigley HA. Number of people with glaucoma worldwide. $\mathrm{Br} J$ Ophthalmol. 1996;80(5):389-393.

2. Natarajan JV, Ang M, Darwitan A, Chattopadhyay S, Wong TT, Venkatraman SS. Nanomedicine for glaucoma: liposomes provide sustained release of latanoprost in the eye. Int J Nanomedicine. 2012 7:123-131.

3. Carvalho IM, Marques CS, Oliveira RS, Coelho PB, Costa PC, Ferreira DC. Sustained drug release by contact lenses for glaucoma treatment - a review. J Control Release. 2015;202:76-82.

4. Dai Y, Zhou R, Liu L, Lu Y, Qi J, Wu W. Liposomes containing bile salts as novel ocular delivery systems for tacrolimus (FK506): in vitro characterization and improved corneal permeation. Int J Nanomedicine. 2013;8:1921-1933.

5. Li X, Zhang Z, Li J, Sun S, Weng Y, Chen H. Diclofenac/biodegradable polymer micelles for ocular applications. Nanoscale. 2012; 4(15):4667-4673.

6. Zimmer A, Kreuter J. Microspheres and nanoparticles used in ocular delivery systems. Adv Drug Deliv Rev. 1995;16(1):61-73.

7. Kaur IP, Garg A, Singla AK, Aggarwal D. Vesicular systems in ocular drug delivery: an overview. Int J Pharm. 2004;269(1):1-14.

8. Almeida AJ, Souto E. Solid lipid nanoparticles as a drug delivery system for peptides and proteins. Adv Drug Deliv Rev. 2007;59(6):478-490.

9. Guan Q, Chen W, Hu X. Development of lovastatin-loaded poly(lactic acid) microspheres for sustained oral delivery: in vitro and ex vivo evaluation. Drug Des Devel Ther. 2015;9:791-798.

10. He P, Liu H, Tang Z, et al. Poly(ester amide) blend microspheres for oral insulin delivery. Int J Pharm. 2013;455(1-2):259-266.

11. Okamoto T, Uemoto S, Tabata Y. Prevention of trinitrobenzene sulfonic acid-induced experimental colitis by oral administration of a poly(lacticcoglycolic acid) microsphere containing prostaglandin E(2) receptor subtype 4 agonist. $J$ Pharmacol Exp Ther. 2012;341(2):340-349.

12. Gavini E, Rassu G, Haukvik T, Lanni C, Racchi M, Giunchedi P. Mucoadhesive microspheres for nasal administration of cyclodextrins. J Drug Target. 2009;17(2):168-179.

13. Huh Y, Cho HJ, Yoon IS, et al. Preparation and evaluation of spray-dried hyaluronic acid microspheres for intranasal delivery of fexofenadine hydrochloride. Eur J Pharm Sci. 2010;40(1):9-15.

14. Andres-Guerrero V, Zong M, Ramsay E, et al. Novel biodegradable polyesteramide microspheres for controlled drug delivery in ophthalmology. J Control Release. 2015;211:105-117.

15. Allison SD. Analysis of initial burst in PLGA microparticles. Expert Opin Drug Deliv. 2008;5(6):615-628.

16. Nilkumhang S, Basit AW. The robustness and flexibility of an emulsion solvent evaporation method to prepare $\mathrm{pH}$-responsive microparticles. Int J Pharm. 2009;377(1-2):135-141.

17. Yeo Y, Park K. Control of encapsulation efficiency and initial burst in polymeric microparticle systems. Arch Pharm Res. 2004;27(1):1-12.

18. Zhang W, Li X, Ye T, et al. Nanostructured lipid carrier surface modified with Eudragit RS 100 and its potential ophthalmic functions. Int $J$ Nanomedicine. 2014;9:4305-4315.
19. Pignatelloa R, Bucolob C, Spedalieria G, Malteseb A, Puglisia G. Eudragit $\mathrm{RS} 100^{\circledR}$ nanosuspensions for the ophthalmic controlled delivery of ibuprofen. Eur J Pharm Sci. 2002;16(1-2):53-61.

20. Pignatelloa R, Bucolob C, Spedalieria G, Malteseb A, Puglisia G. Flurbiprofen-loaded acrylate polymer nanosuspensions for ophthalmic application. Biomaterials. 2002;23(15):3247-3255.

21. Ennajih H, Bouhfid R, Essassi EM, Bousmina M, El Kadib A. Chitosanmontmorillonite bio-based aerogel hybrid microspheres. Microporous Mesoporous Mater. 2012;152:208-213.

22. dos Santos BR, Bacalhau FB, Pereira Tdos S, Souza CF, Faez R. Chitosan-montmorillonite microspheres: a sustainable fertilizer delivery system. Carbohydr Polym. 2015;127:340-346.

23. Hou D, Gui R, Hu S, Huang Y, Feng Z, Ping Q. Preparation and characterization of novel drug-inserted-montmorillonite chitosan carriers for ocular drug delivery. Adv Nanoparticles. 2015;4(3):70-84.

24. Hou D, Hu S, Huang Y, et al. Preparation and in vitro study of lipid nanoparticles encapsulating drug loaded montmorillonite for ocular delivery. Appl Clay Sci. 2016;119(2):277-283.

25. Huang Y, Tao Q, Hou D, et al. A novel ion exchange carrier based upon liposome-incorporated montmorillonite for ophthalmic delivery of betaxolol hydrochloride. Int J Nanomedicine. 2017;12:1-15.

26. Zheng JP, Luan L, Wang HY, Xi LF, Yao KD. Study on ibuprofen/ montmorillonite intercalation composites as drug release system. Appl Clay Sci. 2007;36(4):297-301.

27. Anirudhan TS, Sandeep S. Synthesis and characterization of a novel $\mathrm{pH}$-controllable composite hydrogel for anticancer drug delivery. New J Chem. 2011;35(12):2869.

28. Shameli K, Bin Ahmad M, Zargar M, et al. Synthesis and characterization of silver/montmorillonite/chitosan bionanocomposites by chemical reduction method and their antibacterial activity. Int J Nanomedicine. 2011;6:271-284

29. Kevadiya BD, Joshi GV, Bajaj HC. Layered bionanocomposites as carrier for procainamide. Int J Pharm. 2010;388(1-2):280-286.

30. Jelvehgari M, Barar J, Valizadeh H, Shadrou S, Nokhodchi A. Formulation, characterization and in vitro evaluation of theophylline-loaded Eudragit RS 100 microspheres prepared by an emulsion-solvent diffusion/ evaporation technique. Pharm Dev Technol. 2011;16(6):637-644.

31. Casolaro M, Casolaro I, Lamponi S. Stimuli-responsive hydrogels for controlled pilocarpine ocular delivery. Eur J Pharm Biopharm. 2012; 80(3):553-561.

32. Vinardell MP, Garcia L. The quantitive chlorioallantoic membrance test using trypan blue stain to predict the eye irritancy of liquid scintillation cocktails. Toxicol In Vitro. 2000;14(6):551-555.

33. Nascimento DF, Silva AC, Mansur CR, et al. Characterization and evaluation of poly( $\varepsilon$-caprolactone) nanoparticles containing 2-ethylhexylp-methoxycinnamate, octocrylene, and benzophenone-3 in anti-solar preparations. J Nanosci Nanotechnol. 2012;12(9):7155-7166.

34. Nguyen DH, Beuerman RW, Wever BD, Rosdy M. Three-dimensional construct of the human corneal epithelium for in vitro toxicology. In: Salem H, Katz SA, editors. Alternative Toxicological Methods. Boca Rato: CRC Press; 2003:147-159.

35. York M, Steiling W. A critical review of the assessment of eye irritation potential using the Draize rabbit eye test. J Appl Toxicol. 1998;18(4): 233-240.

36. Moosa RM, Choonara YE, du Toit LC, et al. In vivo evaluation and in-depth pharmaceutical characterization of a rapidly dissolving solid ocular matrix for the topical delivery of timolol maleate in the rabbit eye model. Int J Pharm. 2014;466(1-2):296-306.

37. Morrison JC, Moore CG, Deppmeier LMH, Gold BG, Meshul CK, Johnson EC. A rat model of chronic pressure-induced optic nerve damage. Exp Eye Res. 1997;64(1):85-96.

38. Zaghouane-Boudiaf H, Boutahala M. Kinetic analysis of 2,4,5trichlorophenol adsorption onto acid-activated montmorillonite from aqueous solution. Int J Miner Process. 2011;100(3-4):72-78.

39. Momoh MA, Kenechukwu FC, Adedokun MO, Odo CE, Attama AA. Pharmacodynamics of diclofenac from novel Eudragit entrapped microspheres. Drug Deliv. 2014;21(3):193-203. 
40. Mundargi RC, Rangaswamy V, Aminabhavi TM. pH-Sensitive oral insulin delivery systems using Eudragit microspheres. Drug Dev Ind Pharm. 2011;37(8):977-985.

41. Haznedar S, Dortunç B. Preparation and in vitro evaluation of Eudragit microspheres containing acetazolamide. Int J Pharm. 2004;269(1): 131-140.

42. Dong Y, Feng SS. Poly(d,1-lactide-co-glycolide)/montmorillonite nanoparticles for oral delivery of anticancer drugs. Biomaterials. 2005; 26(30):6068-6076.

43. Mendioroz S, Pajares JA, Benito I, Pesquera C, Gonzalez F, Blanco C. Texture evolution of montmorillonite under progressive acid treatment: change from $\mathrm{H}_{3}$ to $\mathrm{H}_{2}$ type of hysteresis. Langmuir. 1987;3(5): 676-681.

44. Gupta H, Aqil M, Khar RK, Ali A, Bhatnagar A, Mittal G. Sparfloxacinloaded PLGA nanoparticles for sustained ocular drug delivery. Nanomedicine. 2010;6(2):324-333.

45. Hagino S, Itagaki H, Kato S, Kobayashi T, Tanaka M. Quantitative evaluation to predict the eye irritancy of chemicals: modification of chorioallantoic membrane test by using trypan blue. Toxicol In Vitro. 1991;5(4):301-304.
46. Qin F, Zeng L, Zhu Y, Cao J, Wang X, Liu W. Preparation and evaluation of a timolol maleate drug-resin ophthalmic suspension as a sustained-release formulation in vitro and in vivo. Drug Dev Ind Pharm. 2016;42(4):535-545.

47. Hong S, Seong GJ, Hong YJ. Long-term intraocular pressure fluctuation and progressive visual field deterioration in patients with glaucoma and low intraocular pressures after a triple procedure. Arch Ophthalmol. 2007;125(8):1010-1013.

48. Konstas AGP, Mantziris DA, Cate EA, Stewart WC. Effect of timolol on the diurnal intraocular pressure in exfoliation and primary open-angle glaucoma. Arch Ophthalmol. 1997;115(8):975-979.

49. Medeiros FA, Pinheiro A, Moura FC, Leal BC, Susanna R. Intraocular pressure fluctuations in medical versus surgically treated glaucomatous patients. J Ocul Pharmacol Ther. 2002;18(6):489-498.
International Journal of Nanomedicine

\section{Publish your work in this journal}

The International Journal of Nanomedicine is an international, peerreviewed journal focusing on the application of nanotechnology in diagnostics, therapeutics, and drug delivery systems throughout the biomedical field. This journal is indexed on PubMed Central, MedLine, CAS, SciSearch $\AA$, Current Contents ${ }^{\circledR} /$ Clinical Medicine,

\section{Dovepress}

Journal Citation Reports/Science Edition, EMBase, Scopus and the Elsevier Bibliographic databases. The manuscript management system is completely online and includes a very quick and fair peer-review system, which is all easy to use. Visit http://www.dovepress.com/ testimonials.php to read real quotes from published authors. 